\title{
Transhiatal esophagogastrectomy for an isolated ovarian cancer metastasis to the esophagus
}

\author{
John C. Haney, MD, and Thomas A. D'Amico, MD, Durham, NC
}

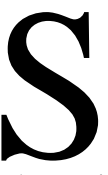

econdary involvement of the esophagus by malignancy is rare, occurring in patients with cancer at an estimated incidence of $1 \%$ to $6 \%{ }^{1-3}$ Although primary cancers of the lung and breast are most commonly responsible, other primary sites have included tumors of the prostate, skin, kidney, bladder, rectum, pancreas, thyroid, liver, and endometrium. ${ }^{3,4}$ Esophageal metastasis from ovarian cancer has been reported in only 1 case, in which the metastasis occurred 16 years after initial tumor resection and was treated with partial esophagectomy. ${ }^{1,2}$ This report describes a case of metastatic ovarian cancer to the esophagus after a 4-year disease-free interval.

\section{Clinical Summary}

A 58-year-old woman had a 2-month history of dysphagia. Four years previously, she had undergone complete resection of a $21-\mathrm{cm}$ clear cell ovarian neoplasm with positive bilateral pelvic and periaortic lymph nodes, followed by chemotherapy. Computed tomographic scan 1 year after surgery demonstrated no progression, and the patient remained free of symptoms until the dysphagia developed.

A computed tomographic scan obtained at that time revealed a mass in the midesophagus (Figure 1), and esophageal ultrasonography demonstrated a partially obstructing tumor that appeared to involve the submucosa. A biopsy sample demonstrated adenocarcinoma, consistent with ovarian metastases. The patient underwent positron emission tomography, which revealed no extrathoracic disease. After multidisciplinary consultation, the decision was made to undertake surgical resection, to be followed by adjuvant chemotherapy.

During the operation, the tumor appeared to be adherent to but not invasive of the aorta and was mobilized without difficulty. Examination of the liver, diaphragm, and peritoneum revealed no evidence of metastatic disease. Transhiatal resection with cervical esophagogastric anastomosis was performed without difficulty. The patient was discharged without complication on postoperative day 7.

Pathologic examination of the specimen revealed a $7-\mathrm{cm}$ midesophageal mass, with invasion into the muscularis. All sur-

From Duke University Medical Center, Durham, NC.

Received for publication Dec 9, 2003; revisions received Jan 2, 2004; accepted for publication Jan 13, 2004.

Address for reprints: Thomas A. D'Amico, MD, Associate Professor of Surgery, Duke University Medical Center, Box 3496, Durham, NC 27710 (E-mail: damic001@mc.duke.edu).

J Thorac Cardiovasc Surg 2004;127:1835-6

$0022-5223 / \$ 30.00$

Copyright (C) 2004 by The American Association for Thoracic Surgery

doi:10.1016/j.jtcvs.2004.01.018

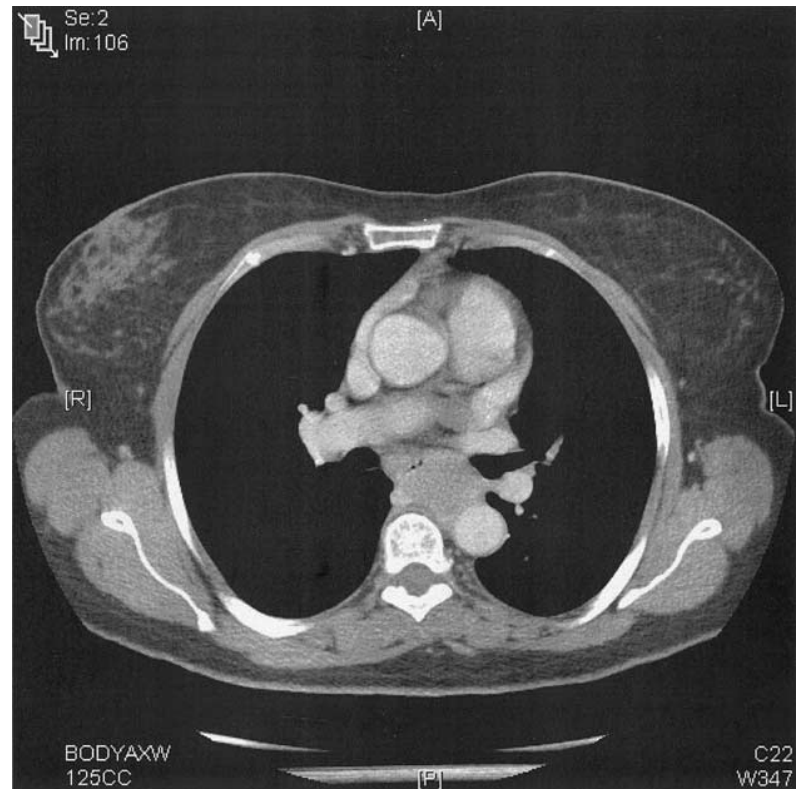

Figure 1. Computed tomographic scan demonstrates mass in midesophagus, without evidence of involvement of aorta or airway.

gical margins were negative, and only 1 regional lymph node was positive. The tumor was characterized as ovarian adenocarcinoma, clear cell variant. It demonstrated immunoreactivity to CA-125, cytokeratin 7, and carcinoembryonic antigen but not cytokeratin 20 . Both the histologic and immunoreactivity profiles were identical to those of the patient's previous ovarian carcinoma, and a diagnosis of metastatic ovarian carcinoma was confirmed.

\section{Discussion}

Metastases to the esophagus are rare, estimated to occur in $1 \%$ of patients with cancer., ${ }^{2,3}$ Our case appears to be only the second reported case of metastasis to the esophagus from ovarian carcinoma. ${ }^{1,2}$ A review of 62 cases of secondary esophageal neoplasms estimated that $45 \%$ were the result of direct extension, $36 \%$ were due to lymphatic spread from mediastinal nodes, and $19 \%$ occurred from hematogenous seeding. ${ }^{4}$ Ovarian cancers are notorious for early metastasis, and spread to the thoracic cavity is relatively common, with incidence estimates ranging from $7 \%$ to $44.5 \%$ of patients with ovarian cancer, although thoracic involvement without liver metastases occurs only $3 \%$ of the time. ${ }^{2,5}$

Treatment of esophageal metastases is difficult, especially in cases of direct extension or lymphatic invasion. In most cases, patients are treated with palliative radiation or chemotherapy. In some cases, however, especially those in which a solitary metas- 
tasis is encountered, the lesion may be amenable to surgical resection. ${ }^{6}$ Fujii and colleagues ${ }^{6}$ have advocated the resection of solitary breast cancer metastases followed by chemotherapy when local control may be achieved, and when the disease-free interval has been long, indicative of a slow-growing primary tumor. Oka and associates ${ }^{7}$ reported on resection of a metastasis from a lung cancer primary after a latency period of 5 years; the patient remained without recurrence 23 months after resection. Mizobuchi and colleagues ${ }^{2}$ reported on 3 cases of esophagectomy, including the one previous patient with an ovarian cancer metastasis; longterm survivals of 4 and 14 years were achieved in patients in which the disease-free intervals had been 7 and 16 years, respectively.

In the case of our patient, the solitary esophageal metastasis was seen after a disease-free interval of approximately 4 years. Positron emission tomographic scan did not detect extrathoracic disease, and local control of the tumor appeared achievable. Because of the patient's age and relative health, resection followed by adjuvant therapy was pursued. The choice to perform resection before chemotherapy is consistent with the strategy to perform surgical debulking before systemic therapy for ovarian cancer; however, the use of preoperative chemotherapy followed by surgical resection would seem to be equally feasible. Although the ultimate prognosis of esophageal metastases is poor, effective symptom resolution and long-term disease-free interval are achievable goals for resection. Appropriate patients would include those in sufficiently good preoperative health with solitary metastasis from slow-growing tumors, as evidenced by a relatively long symptom-free interval. For effective resection with an acceptable level of morbidity, the transhiatal approach is advocated.

\section{References}

1. Asamura H, Goya T, Hirata K, Suemasu K, Itabashi M, Matsuno Y, et al. Esophageal and pulmonary metastases from ovarian carcinoma: a case report of long-term survival following metastatic resections. Jpn J Clin Oncol. 1991;21:211-7.

2. Mizobuchi S, Tachimori Y, Kato H, Watanabe H, Nakanishi Y, Ochiai A. Metastatic esophageal tumors from distant primary lesions: report of three esophagectomies and study of 1835 autopsy cases. Jpn J Clin Oncol. 1997;27:410-4.

3. Anderson MF, Harell GS. Secondary esophageal tumors. AJR Am J Roentgenol. 1980;135:1243-6.

4. Agha FP. Secondary neoplasms of the esophagus. Gastrointest Radiol. 1987; $12: 187-93$.

5. Dauplat J, Neville F, Hacker NF, Nieberg RK, Berek JS, Rose TP, et al. Distant metastases in epithelial ovarian carcinoma. Cancer. 1987;60: 1561-6.

6. Fujii K, Nakanishi Y, Ochiai A, Tsuda H, Yamaguchi H, Tachimori Y, et al. Solitary esophageal metastasis of breast cancer with 15 Years' latency: a case report and review of the literature. Pathol Int. 1997;47: 614-7.

7. Oka T, Ayabe H, Kawahara K, Tagawa Y, Hara S, Tsuji H, et al. Esophagectomy for metastatic carcinoma of the esophagus from lung cancer. Cancer. 1993;71:2958-61.

\title{
Massive pneumoencephalus of late onset after an en bloc resection for lung cancer
}

\author{
Marco Lucchi, MD, Paolo Dini, MD, Francesco Givigliano, MD, Alessandro Ribechini, MD, and Alfredo Mussi, MD, \\ Pisa, Italy
}

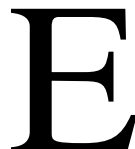

xtended resections are considered a valid therapeutic option in cases of selected locally advanced lung cancer in reason of an acceptable morbidity. ${ }^{1-3}$ Multimodality treatment, including chemotherapy, radiotherapy, and surgical intervention, has proved to improve the results in terms of disease-free and overall survival, ${ }^{4-6}$ despite a major postoperative morbidity. $^{7}$

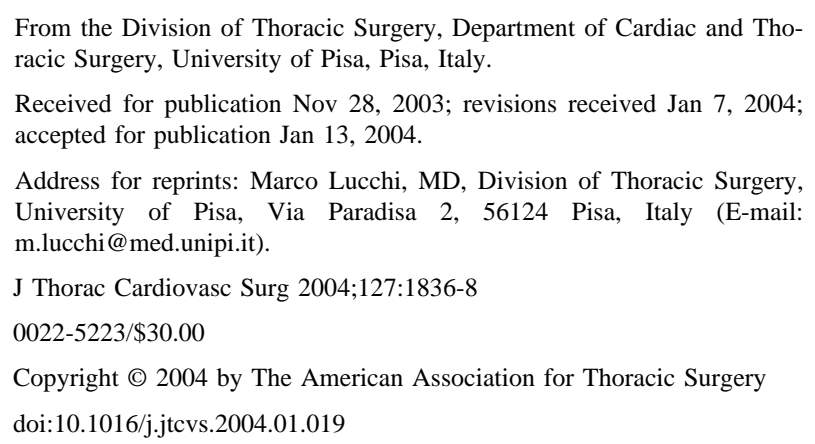

Pneumoencephalus is a rare complication of important cranial trauma $^{8}$ or neurosurgery, ${ }^{9}$ but to our knowledge, it was never reported after thoracic surgery. We report a case of massive pneumoencephalus appearing late after an en bloc upper right lobectomy for lung cancer in a patient who previously underwent chemoradiotherapy. Thoracic surgeons should be aware of this possible complication when an extended lung resection involving the ribs and the vertebral bodies is performed.

\section{Clinical Summary}

A 76-year-old man was referred for surgical treatment of right upper lobe squamous carcinoma infiltrating the chest wall. Previously, the patient underwent 3 cycles of neoadjuvant chemotherapy (carboplatin and paclitaxol) and radiotherapy (40 Gy) with a partial response $(<50 \%)$. At the operation, we performed an en bloc right upper lobectomy with the posterior arches of the first 4 ribs and the transverse process of D2.

The postoperative course was uneventful, and the patient was discharged on the ninth day. The pathologic examination showed 